\title{
Thermal comfort range and influence factor of urban pedestrian streets in severe cold regions
}

\author{
Hong Jin ${ }^{\mathrm{a}}$, Siqi Liu ${ }^{\mathrm{a}}$, Jian Kang ${ }^{\mathrm{a}, \mathrm{b}, \text { * }}$ \\ ${ }^{a}$ School of Architecture, Harbin Institute of Technology; Key Laboratory of Cold Region Urban \\ and Rural Human Settlement Environment Science and Technology, Ministry of Industry and \\ Information Technology, No. 66, Xidazhi Street, Harbin, Heilongjiang, China \\ ${ }^{b}$ UCL Institute for Environmental Design and Engineering, The Bartlett, University College \\ London (UCL), Central House, 14 Upper Woburn Place, London WC1HONN, UK \\ * Corresponding author
}

\begin{abstract}
This study investigated thermal comfort on two urban pedestrian streets in Harbin, which is an extremely cold region with significant temperature variability, through an on-site survey to determine the thermal comfort range and influence factor. The results show that the 'acceptable' votes above $80 \%$ in Harbin are in the range of $-3.8-23.0{ }^{\circ} \mathrm{C}$ universal thermal climate index (UTCl). The neutral temperatures in transition and hot seasons are $21.4{ }^{\circ} \mathrm{C}$ and $21.8{ }^{\circ} \mathrm{C} \mathrm{UTCl}$, respectively, and participants are more sensitive to the thermal environment during the hot season. The thermal sensation vote values of the preferred temperatures in transition and hot seasons are 0.48 and 0.65 , respectively. This indicates that people expect a 'neutral slightly warm' thermal sensation. The modified UTCl range in Harbin is wider compared to those in Tianjin and the Mediterranean, whereas the UTCI for extreme cold stress reaches $-30.2{ }^{\circ} \mathrm{C}$. Thermal adaptation and demographic factors also have a significant impact on thermal comfort. Working people always feel colder than walking people, and in the cold season, people who have lived in Harbin longer feel more comfortable. Males feel more comfortable than females, whereas older people are more adaptable to extreme weather conditions.
\end{abstract}

Keywords: Thermal Comfort, Pedestrian Street, Severe Cold Region, Thermal Adaptation 2019 Energy and Buildings

Date Received: 6 February 2019 Date Accepted: 25 May 2019

Available online: 25 May 2019 


\section{Introduction}

Outdoor public space is an important part of the living environment, as people often have to expose themselves to outdoor public spaces for leisure and entertainment. Research conducted by Eliasson et al. [1] in Gothenburg showed that the impact of the clearness index, air temperature, and wind speed on the number of people in public spaces accounted for more than $50 \%$ of the variance. Their research indicates that these three climatic factors have a significant impact on the behaviour of people. Knes and Thorsson [2] found that when the level of thermal comfort is within an acceptable range, people tend to stay outdoors longer (average 19-21 min), whereas when they feel uncomfortable, they stay outdoors for shorter periods (average $11 \mathrm{~min}$ ). Therefore, the efficiency of an outdoor public space is influenced by the level of thermal comfort. As winter in severe cold cities is long and frigid [3], outdoor conditions may reduce outdoor activities.

Previous studies have shown that there are some differences in the thermal requirements of people in different regions. Taiwan, Arizona, Shanghai and Nagoya can be considered as examples of subtropical regions. The neutral temperatures, which indicate that people neither feel warm nor cold, are $25.6{ }^{\circ} \mathrm{C}$ and $23.7^{\circ} \mathrm{C}$ predicted mean vote (PET) for the hot and hot seasons, respectively in Taiwan [4]. According to research conducted by Middel et al. [5], the neutral temperature is $28.6{ }^{\circ} \mathrm{C}$ PET in Tempe, Arizona. The neutral temperature in winter in Shanghai is approximately $15-29{ }^{\circ} \mathrm{C}$ PET [6]. The neutral temperature measured using the universal thermal climate index (UTCl) in Nagoya is $34.0^{\circ} \mathrm{C}$ [7]. Quebec and Tianjin can be considered as examples of temperate regions. Provençal1 et al. [8] found that the range of no thermal stress is $9-26{ }^{\circ} \mathrm{C} \mathrm{UTCl}$ in Quebec. Lai et al. [9] compared the neutral UTCl in different regions and found that the range of no thermal stress is $12-25^{\circ} \mathrm{C} \mathrm{UTCl}$ in Tianjin. Some European countries can also be considered as examples of Mediterranean regions. A study by Nikolopoulou and Lykoudis [10] showed that neutral temperatures exhibited a large variation of over $10{ }^{\circ} \mathrm{C}$ across Europe. For example, the annual neutral temperatures in Athens and Fribourg are $23{ }^{\circ} \mathrm{C}$ and $13{ }^{\circ} \mathrm{C}$, respectively. The above results indicate that people may have different thermal preferences under different climatic conditions. However, these studies were conducted in temperate and subtropical regions and did not include severe cold regions.

Since comfort is a state of mind, it is influenced not only by the physical parameters of the environment, but also by social, cultural, and psychological issues [11]. The thermal requirements in different regions and in different seasons vary owing to thermal adaptation and other factors including thermal experience, thermal expectations, perception control, culture, and exposure time [12]. For instance, research conducted by Lin [4] in a square in Taiwan showed that the level of self-choice has a significant effect on thermal comfort. When individuals chose to visit a certain place freely (for instance for a walk or for rest), they often felt very satisfied with the thermal environment. However, when the level of self-choice is low, that is, when people must pass through a certain place, their satisfaction with the thermal environment is often very low. Research conducted by Chen et al. [6] in a park in Shanghai in autumn and winter found that an individual's local residence time in the city will affect the thermal comfort of the individual; people who had been living in Shanghai for a long time seemed to be more adaptable to local weather. There is also a clear correlation between thermal comfort and individual characteristics such as demographic factors (age and gender), metabolism, and thermal resistance of clothes [13]. A study conducted by Andrade et al. [14] in Lisbon, Portugal, found that the proportion of people who felt uncomfortable in the thermal environment decreased with increasing age. A study conducted by Lan et al. [15] in Shanghai, China, found that females were more sensitive to change in temperature and preferred neutral or slightly warmer days; thus, their comfortable operative temperature $\left(26.3^{\circ} \mathrm{C}\right)$ was higher 
than that of males $\left(25.3^{\circ} \mathrm{C}\right)$. However, a study in Nanjing, China, showed that males and females had a similar preference for the highest comfortable temperature [16]. These studies indicate that thermal adaptation and demographic factors may influence thermal comfort.

Because thermal comfort varies from region to region, this study focused mostly on the severe cold regions of northeast China and explored the outdoor thermal comfort features of such regions, which are different from other regions. An on-site survey of two pedestrian streets was conducted using a combination of subjective investigation of thermal comfort and measurement of the urban thermal environment. This study aims to determine the range of UTCI that represents people's feeling of comfort, as well as to investigate the influence of demographic factors (age and gender) and thermal adaptation factors (thermal experience, thermal expectation, local residence time, and so forth) on the thermal comfort of people on the streets.

\section{Materials and Methods}

\subsection{Study area}

The study was conducted in Harbin ( $125^{\circ} 42^{\prime}-130^{\circ} 10^{\prime} \mathrm{E}$, $44^{\circ} 04^{\prime}-46^{\circ} 40^{\prime} \mathrm{N}$, altitude: $180-200$ $\mathrm{m})$, located in northeast China. In terms of the building climate demarcation of China, the city belongs to a severe cold region [17-19]. Fig. 1 shows the monthly average air temperatures and wind speeds in Harbin from 1988 to 2010 (according to data from the no. 50,953 weather station in Harbin, which belongs to the National Meteorological Information Center of China). The monthly average air temperature reached the highest value of $23.2{ }^{\circ} \mathrm{C}$ in July and the lowest value of $-17.5^{\circ} \mathrm{C}$ in January. The monthly average wind speed fluctuates in the range of 2.4-3.7 m/s. In the QX/T 152-2012 division of climate season standard issued by the China Meteorological Administration, the average daily temperature in winter is less than $10{ }^{\circ} \mathrm{C}$, the average daily temperature in summer is higher than or equal to $22^{\circ} \mathrm{C}$, and the average daily temperature in spring and autumn is higher than or equal to $10{ }^{\circ} \mathrm{C}$, but less than $22{ }^{\circ} \mathrm{C}$. According to this standard, the winter period in Harbin is from October to April, the spring period is in May and June, the summer period is in July, and the autumn period is in August and September (Because the average air temperature in June and August is $21.17^{\circ} \mathrm{C}$ and $21.33^{\circ} \mathrm{C}$, respectively, which is very close to $22^{\circ} \mathrm{C}$, the late June and early August are classified as summer. The average air temperature in April is $8.17^{\circ} \mathrm{C}$, which is very close to $10^{\circ} \mathrm{C}$, so that late April is classified as spring). As spring and autumn are both transitional periods between summer and winter, they are referred to as 'transition seasons' in this study, whereas winter and summer are referred to as the 'cold season' and 'hot season', respectively.

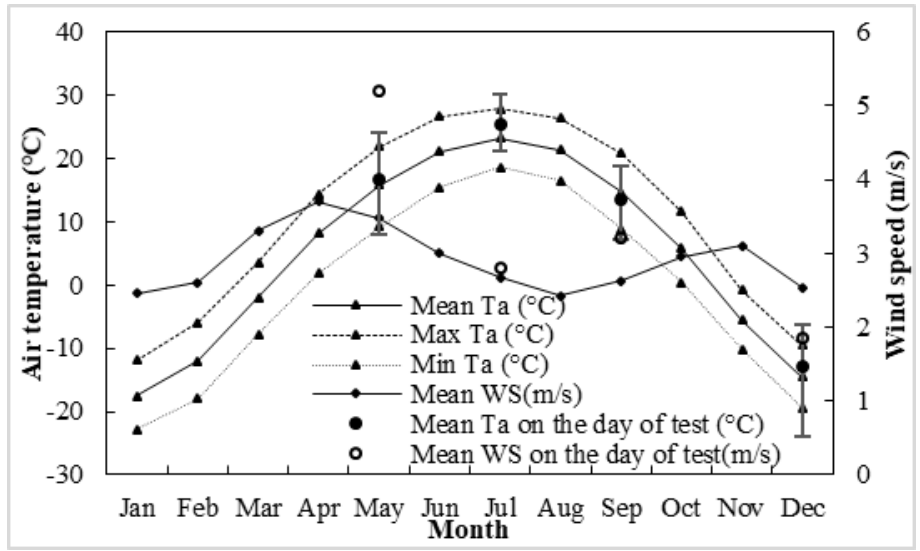

Fig. 1. Monthly average air temperature and wind speed from 1988 to 2010 . Positive and negative error lines indicate the highest and lowest values of the date of on-site investigation, respectively. 
Central Avenue and Majiagou River Pedestrian Street were selected as the on-site investigation areas. Fig. 2 shows the study area and details of the field study. Both streets are popular pedestrian streets in Harbin with a huge volume of human traffic and various categories of visitors. The flow of people on Central Avenue during the peak period can reach 500,000 in one day, and the flow of people at the children's park, through which the portion of Majiagou River Pedestrian Street selected for this study passes, is 20,000 in one day during the peak period $[20,21]$. Central Avenue consists of a main street and several minor streets; the main street is approximately $1.45 \mathrm{~km}$ long. This study selected two sites, namely south and north Central Avenue. Both study sites are north-south streets, with minor streets running perpendicular. In the southern study site, the width of the street is $20 \mathrm{~m}$ and the average height of the buildings on both sides of the street is $16 \mathrm{~m}$. There are trees along some sections of the street, far away from the river. In the northern study site, the width of the street is $50 \mathrm{~m}$ and the average height of the buildings on both sides of the street is $27 \mathrm{~m}$. There are no trees, and the street is approximately $270 \mathrm{~m}$ from the Songhua River. Majiagou River Pedestrian Street is $1.1 \mathrm{~km}$ long. The stretch along the children's park was selected as the study site. The orientation of the street in the study site is north $50^{\circ}$ east, with no buildings on either side. There are shade trees on both sides of the study site, and it is very close to the Majiagou River.

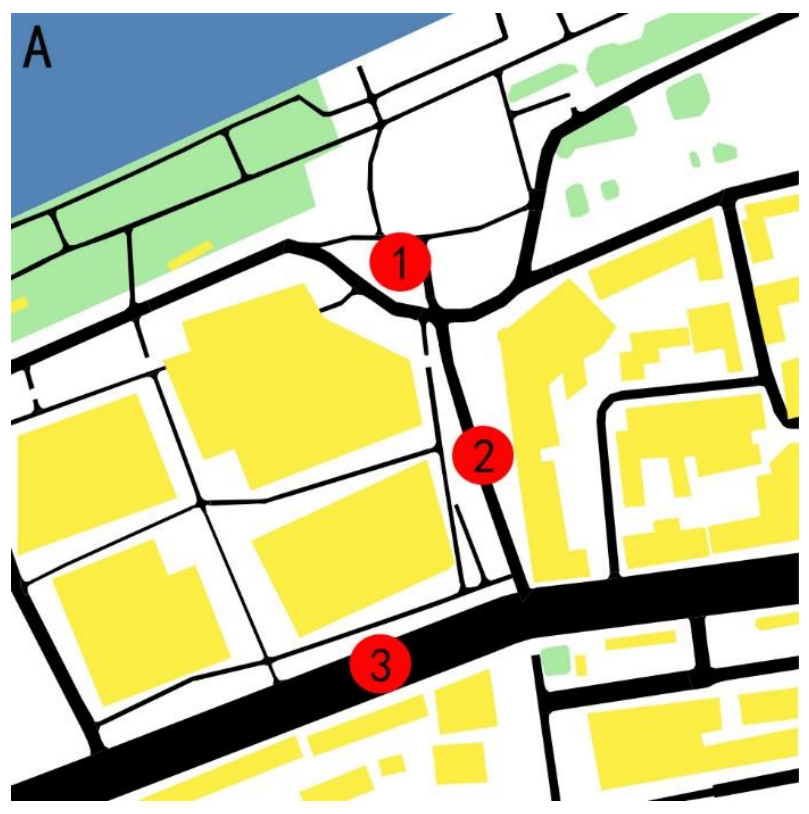

(a) Harbin Central Avenue (northern site)

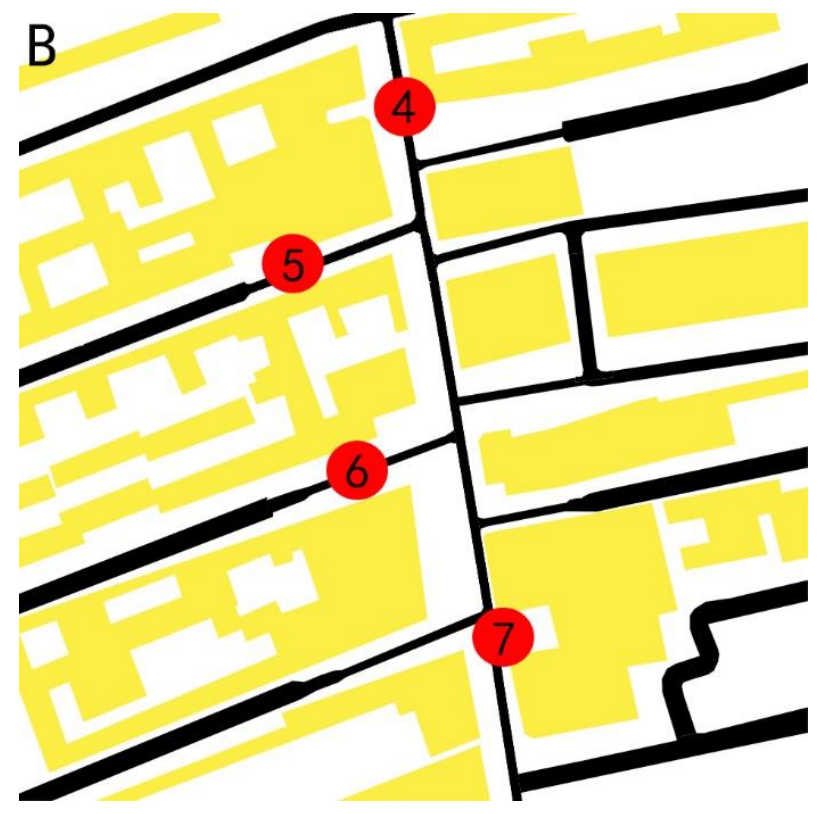

(b) Harbin Central Avenue (southern site) 

doi: 10.1016/j.enbuild.2019.05.054

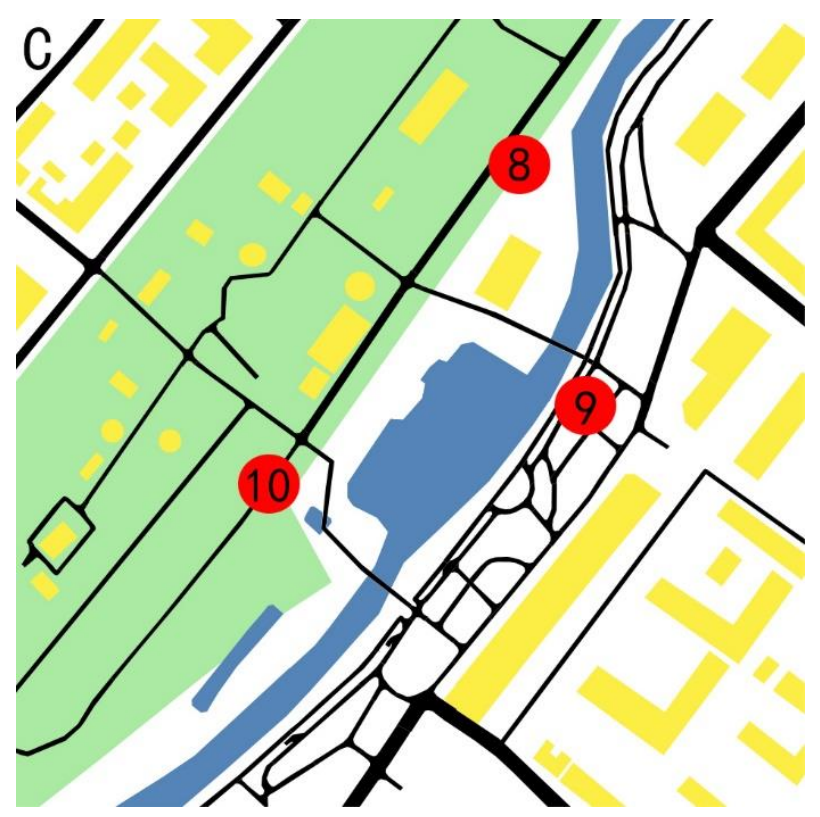

(c) Majiagou River Pedestrian Street

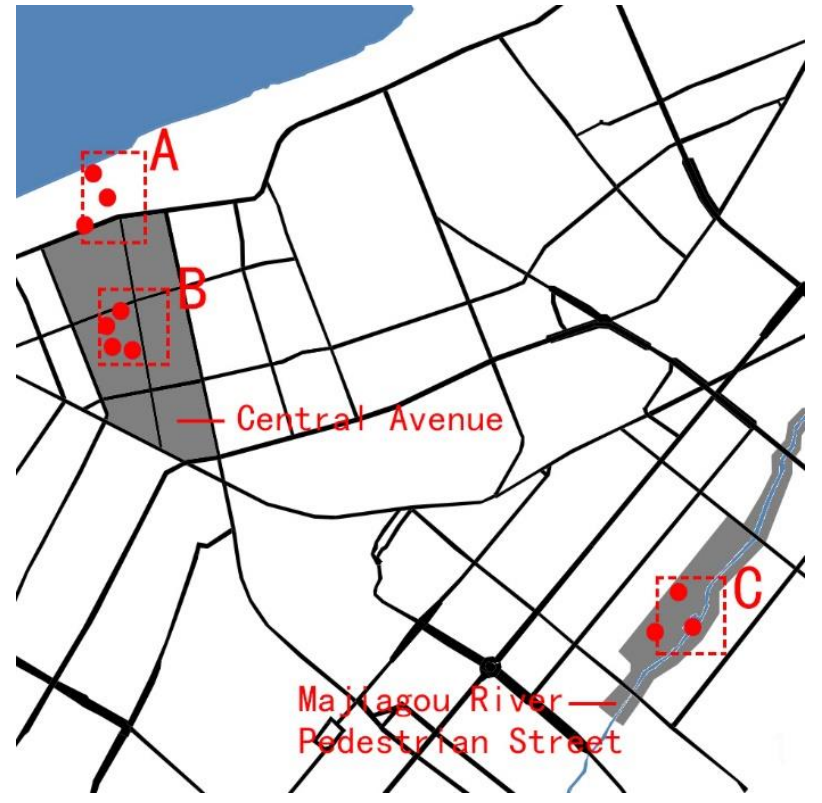

(d) Overall distribution of study sites
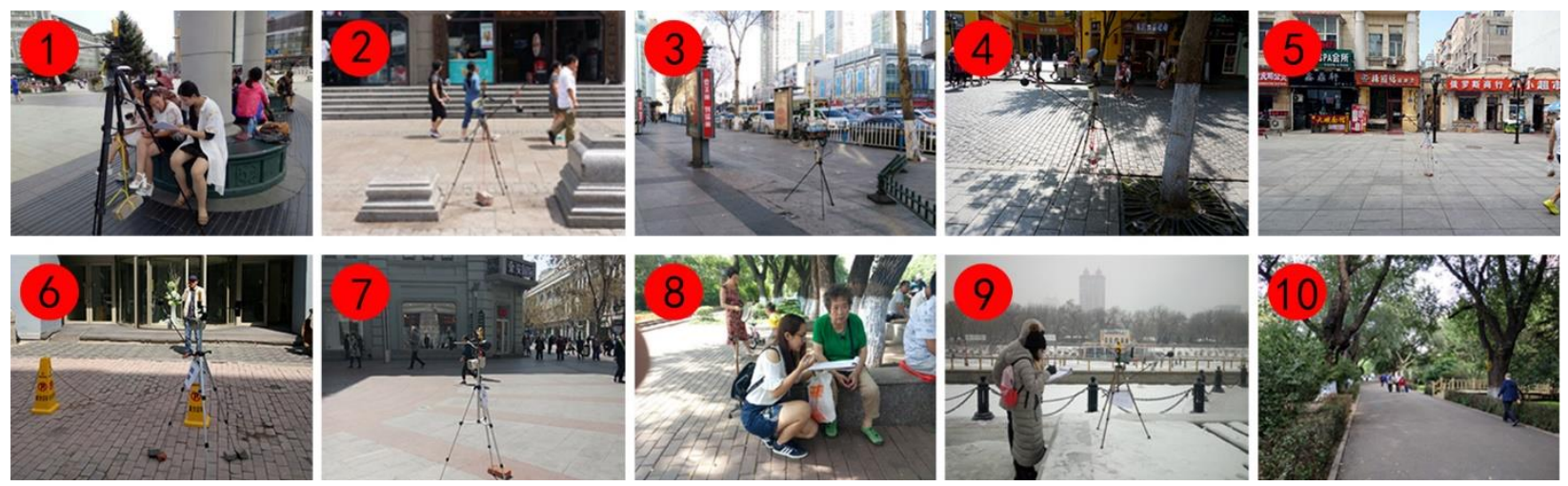

(e) Photographs of field survey scenes

Fig. 2. Study site and distribution map of measurement devices. *The number in the red circle represents the position of the measuring point. *In Fig. 2 (a) through 2(d), the blue represents the water, the green represents the grassland, the yellow represents the architecture, and the black represents the roads. (For interpretation of the references to colour in this figure legend, the reader is referred to the web version of this article.)

\subsection{Field study procedures}

One survey was conducted in January, April, July and September of 2017 in Central Avenue and another survey was conducted in December of 2017 and in May, July and September of 2018 in Majiagou River Pedestrian Street by referring to a previous study [12] , and the survey was conducted once a month for a total of eight surveys, one survey per region and per season. Data obtained in July and January (or December) represent 'hot season' and 'cold season', respectively, whereas data obtained in April, May and September represent the 'transition season'. The duration of each survey was one day. Outdoor activities were most frequent in the period of 9:00-16:00. Therefore, data was collected during this period of the test day. According to the plot in Fig. 1, the average air temperature on the day of the test was near the average daily air temperature. Additionally, the average values of the thermal environment parameters for the two test days in different years in the same season were very similar. 
Between 9:00 and 16:59, the difference in average air temperature was between 0.44 and $3.27^{\circ} \mathrm{C}$, the difference in relative humidity was between 5.01 and $12.72 \% \mathrm{RH}$, the difference in the wind speed was between 0.11 and $0.76 \mathrm{~m} / \mathrm{s}$, and the difference between the globe temperatures was $0.13-4.93{ }^{\circ} \mathrm{C}$. The gender and age distribution for each test day in the respective location was relatively similar. Take Central Avenue as an example. The proportion of females in the four seasons of winter, spring, summer, and autumn was $44 \%, 40 \%, 55 \%$, and $41 \%$, respectively. The proportion of males was $56 \%, 60 \%, 45 \%$, and $59 \%$, respectively. The proportion of people aged $18-30$ was $57 \%, 52 \%, 59 \%$, and $50 \%$; the proportion of people aged $31-40$ was $10 \%, 18 \%, 17 \%$, and $18 \%$; the proportion of people aged $41-50$ was $9 \%$, $13 \%, 11 \%$, and $14 \%$; the proportion of people aged $51-60$ was $10 \%, 8 \%, 4 \%$, and $10 \%$; and the proportion of people aged over 60 was $14 \%, 9 \%, 9 \%$, and $8 \%$. These data indicate that the day of the test was indeed representative. The measurement device was placed as illustrated in Fig. 2, and the thermal comfort survey was conducted for pedestrians near the measurement device. To ensure that the recordings were representative of the composition of the people in the study area, participants were randomly selected to take the survey, and a total of 1868 valid recordings were made during the survey.

\subsection{Objective measurement}

During the measurement of thermal comfort, the air temperature, relative humidity, and globe temperature were recorded using the BES-02 temperature and humidity recorder with air temperature measurement range and accuracy of -30.0 to $50.0^{\circ} \mathrm{C}$ and $\leqslant 0.5^{\circ} \mathrm{C}$, respectively, and relative humidity measurement range and accuracy of $0.0-99.0 \% \mathrm{RH}$ and $\leqslant 3.0 \% \mathrm{RH}$, respectively. The globe temperature was collected using a matt black paint sphere (reflectance: $0.95)$ with a diameter of $0.08 \mathrm{~m}$. The BES-02 temperature and humidity recorder was suspended in a naturally ventilated aluminium film box with high reflectivity to prevent solar radiation. The wind speed was measured using the Kestrel 5500 weather station with a wind speed measurement range of $0.4-40.0 \mathrm{~m} / \mathrm{s}$ and accuracy of $\pm 3.0 \%$. Fig. 2 shows the setup of the measurement devices. The measurement devices were set up in accordance with the ISO 7726 [22] and held by a tripod at a height of approximately $1.1 \mathrm{~m}$ from the ground.

\subsection{Subjective assessment}

The design of the thermal comfort questionnaire was based on existing research and was divided into basic information and thermal comfort sections $[4,8,23]$. The basic information section includes demographic information (gender and age) and psychological factors that affect comfort, such as local residence time and reasons for arriving there. In the thermal comfort section, respondents were asked to describe their thermal sensations and expectations. Thermal sensations were measured using a 7-level scale, namely Cold, Cool, Slightly Cool, Neutral, Slightly Warm, Warm, and Hot. Thermal expectations were measured using a 3-level scale, namely Colder, No Change, and Hotter. Finally, respondents were asked to estimate their overall level of thermal comfort according to climatic conditions, which was measured using a 7-level scale, namely Very Uncomfortable, Uncomfortable, Just Uncomfortable, Neutral, Just Comfortable, Comfortable, and Very Comfortable. 


\subsection{Thermal comfort indices}

The level of outdoor thermal comfort is measured by several different indicators such as predicted mean vote $(\mathrm{PMV})$, effective temperature $(\mathrm{ET} *)$, standard effective temperature (SET*), outdoor standard effective temperature (OUT_SET*) [24,25], wind chill index (WCI), PET, and UTCI, which are all based on the heat balance of the human body. Among these indicators, OUT_SET* and UTCI can accurately and intuitively estimate the thermal environment felt by the human body under constantly changing thermal conditions. This study selected the UTCI as a thermal comfort indicator. The UTCl is appropriate for thermal assessments in all climates, seasons, and scales, as it has been commonly used in related research owing to its universality and rational approach. It represents the actual environment where people have the same physiological reaction as in an equivalent environmental temperature $\left({ }^{\circ} \mathrm{C}\right)$ [26]. A multi-node model based on the adjustment of human body temperature was used to estimate the physiological response to the meteorological environment [27]. UTCI is calculated using UTCI-A002 software, and the corresponding UTCI values are obtained by specifying the air temperature, relative humidity, wind speed, and mean radiation temperature in the software.

The UTCI also considers the clothing model. This study verified the consistency of clothing models between the UTCI and Harbin. In the UTCI clothing model, the overall clothing thermal resistance $\left(\mathrm{I}_{\mathrm{Cl}}\right)$ was estimated using the empirical formula recommended by ISO 9920 as given in Eq. (1), and regression analysis of the average clothing thermal resistance was performed at every $1{ }^{\circ} \mathrm{C}$ air temperature. The Harbin clothing model is also calculated using the same approach. As shown in Fig. 3, the UTCl clothing model and the local clothing model are very consistent in the range of -20 to $20^{\circ} \mathrm{C}$. However, the clothing thermal resistance value of the UTCl clothing model of $\mathrm{T}_{\text {air }}>31.6{ }^{\circ} \mathrm{C}$ had a negative value. This is because the verification range of the UTCl clothing model is within $-20-30^{\circ} \mathrm{C}$, and this range did not exceed $30{ }^{\circ} \mathrm{C}$. This results in a deviation of the UTCl clothing model when the air temperature is above $20^{\circ} \mathrm{C}$ [28]. With an increase in temperature in Harbin, the thermal resistance is infinitely near a certain value $(0.4 \mathrm{clo})$, rather than infinitely decreasing as given in Eq. (2), which is consistent with the result obtained in the Mediterranean region [29]. In general, the UTCI and Harbin clothing models are similar, which indicates that the UTCI indicators are also applicable in Harbin.

$I_{c l}=0.161+0.835 \sum I_{c l u}$

where $\mathrm{I} \mathrm{cl}$ is the intrinsic insulation $\left(\mathrm{m}^{2} \mathrm{KW}^{-1}\right)$ and $\mathrm{I}$ clu is the effective insulation $\left(\mathrm{m}^{2} \mathrm{KW}^{-1}\right)$.

$$
I_{c l}=1 e-0.5 T_{\text {air }}{ }^{3}-0.0005 T_{\text {air }}{ }^{2}-0.0231 T_{\text {air }}+1.3109\left(R^{2}=0.9522\right)
$$

where $\mathrm{T}$ air is the air temperature $\left({ }^{\circ} \mathrm{C}\right)$. 


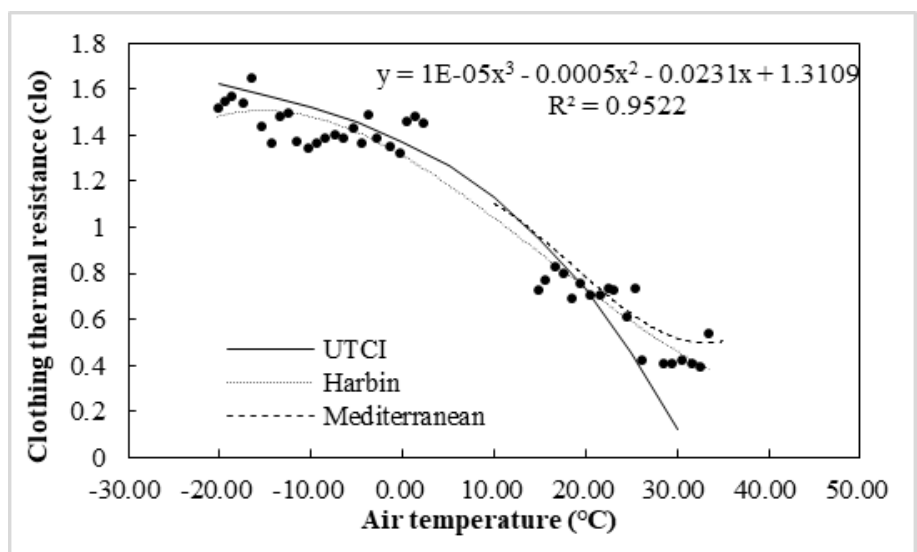

Fig. 3. Fitting curve of clothing thermal resistance and air temperature.

The measured wind speed at a height of $1.1 \mathrm{~m}$ is converted to wind speed at a height of $10 \mathrm{~m}$ using Eq. (3), which is required for calculating the UTCI. In the equation, the measured height is $X(\mathrm{~m})$, the measured wind speed is va $a_{x m}(\mathrm{~m} / \mathrm{s})$, and the converted wind speed is va $(\mathrm{m} / \mathrm{s})$ [30]. The mean radiant temperature is calculated according to the forced convection of the ISO7726 standard as given in Eq. (4) [22]. In this study, the black sphere albedo is 0.95 and its diameter is $0.08 \mathrm{~m}$.

$v a=v a_{x m} \cdot \operatorname{LOG}(10 / 0.01) / \operatorname{LOG}(x / 0.01)$

$T_{M R T}=\left[\left(t_{g}+273\right) \frac{41.1 \cdot 10^{8} \cdot v_{a}^{0.6}}{\varepsilon_{g} \cdot D^{0.4}}\left(t_{g}-t_{a}\right)\right]^{1 / 4}-273$

where TMRT is the mean radiant temperature $\left({ }^{\circ} \mathrm{C}\right)$, $\operatorname{tg}$ is the globe temperature $\left({ }^{\circ} \mathrm{C}\right)$, va is the air velocity $(\mathrm{m} / \mathrm{s})$, ta is the air temperature $\left({ }^{\circ} \mathrm{C}\right), \varepsilon g$ is the emissivity of the black globe, and $D$ is the diameter of the globe $(\mathrm{m})$.

\section{Results}

\subsection{Thermal comfort range}

\subsubsection{Thermal sensation range}

Regression analysis (confidence level 90\%) was performed for the ratio of 'unacceptable' votes (votes outside the three central scales) [31] corresponding to the UTCl at every $1{ }^{\circ} \mathrm{C}$ to determine the acceptable thermal range of people on the streets in Harbin ( Fig. 4 ) (the UTCI was measured at the time the participant was selected; this method was also used to calculate the corresponding UTCl of the participant, as presented in Section 3.1). The categories' sample size for the existing related study to determine the unacceptable range of thermal comfort was estimated before the regression analysis and defined as between 5 and 80 [4,29,31-40]. The minimum sample size for the categories was 5 ; that is, the categories with sample size below 5 were deleted. Ultimately, the minimum sample size for each category was 5 , the maximum sample size was 38 , and the average sample size was 12.91 . The range of acceptable ratios greater than $80 \%$ is calculated as -3.8 to $23.0{ }^{\circ} \mathrm{C}$, which meets the requirement stipulated by ASHRAE55 [41]. However, the 'acceptable' votes above $80 \%$ in the Mediterranean region are in the range of $15.4-26.5{ }^{\circ} \mathrm{C} \mathrm{UTCl}$ [29]. Thus, the acceptable range in various regions is also 
very different, indicating that the psychological characteristics of people have significant impacts on thermal comfort.

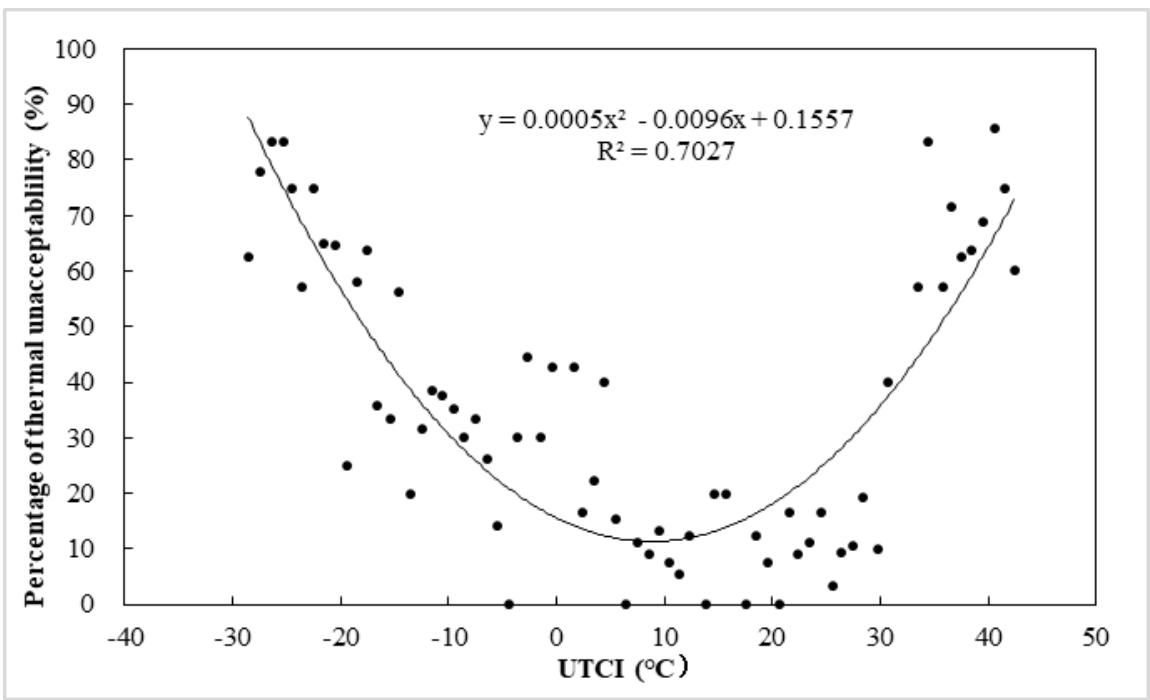

Fig. 4. Unacceptable voting ratio corresponding to UTCI at every $1{ }^{\circ} \mathrm{C}$.

\subsubsection{Neutral UTCI}

Results from previous studies show that people's adaptability to specific environments is influenced by experience at a specific time and place [42]. To verify this claim in Harbin, the method proposed by Lin [4] was adopted in three different seasons to calculate and fit the mean thermal sensation votes (MTSVs) of respondents in each $1{ }^{\circ} \mathrm{C} \mathrm{UTCl}$ interval group. The fitting curve is shown in Fig. 5 (a), and the fitting formulas in three seasons can be obtained, which can be used as the thermal comfort evaluation model based on the UTCI in Harbin. As shown in Fig. 5 (a), the slopes in the cold, transition, and hot seasons are 0.026, 0.053, and 0.130, respectively. The results indicate that people who feel hot outdoors are more sensitive to the thermal environment. One possible reason for this is that the outdoor space in severe cold area has been exposed to low temperature weather for a long period such that people on the streets are less sensitive to low temperature.

The neutral temperature (MTSV $=0$ ) can be calculated using Eqs. $(5)-(7)$. The neutral temperatures for the transition and hot seasons are $21.4{ }^{\circ} \mathrm{C}$ and $21.8{ }^{\circ} \mathrm{C}$, respectively. The neutral temperature for the hot season is slightly higher than that of the transition season, which indicates that people are slightly more accustomed to a hotter environment during the hot season. However, the difference between the two seasons is only $0.4{ }^{\circ} \mathrm{C} \mathrm{UTCl}$ because the summer season in Harbin is very short, such that it is too little time for people in Harbin to adapt to high temperature in summer; thus, the neutral temperature is similar in the transition and hot seasons. The thermal sensation of people on the streets in the cold season is below 0 owing to the very cold climate, and the sensitivity to change in the climate is also very low. Therefore, there is no neutral temperature in the cold season.

Cold season: $M T S V=0.0257$ UTCI $-0.955\left(R^{2}=0.3445\right)$

Transition season: $M T S V=0.0530$ UTCI $-1.1351\left(R^{2}=0.6324\right)$

Hot season: $M T S V=0.1301$ UTCI $-2.8322\left(R^{2}=0.7502\right)$

The neutral temperature is the environmental temperature where people on the streets feel neither cold nor hot outside. However, people do not necessarily feel comfortable under neutral 
temperature. To find the UTCI value that is comfortable for people on the streets, regression analysis was performed on the thermal comfort vote (TCV) and Thermal sensation vote (TSV) at every $1^{\circ} \mathrm{C} \mathrm{UTCl}$ as shown in Fig. 5 (b). When TCV $\geqslant 0$ is determined, the thermal sensation scale value corresponding to the hot season is less than 1.5 , which indicates that people are most comfortable when they feel 'slightly warm' or feel colder than 'slightly warm' in the hot season. In the transition season, people on the streets are in a comfortable environment owing to the mild climate, whereas in cold season, people on the streets are not comfortable owing to the harsh cold thermal environment. The hotter people feel, the more comfortable they will be during the cold and transition seasons, whereas the opposite result is obtained in the hot season.

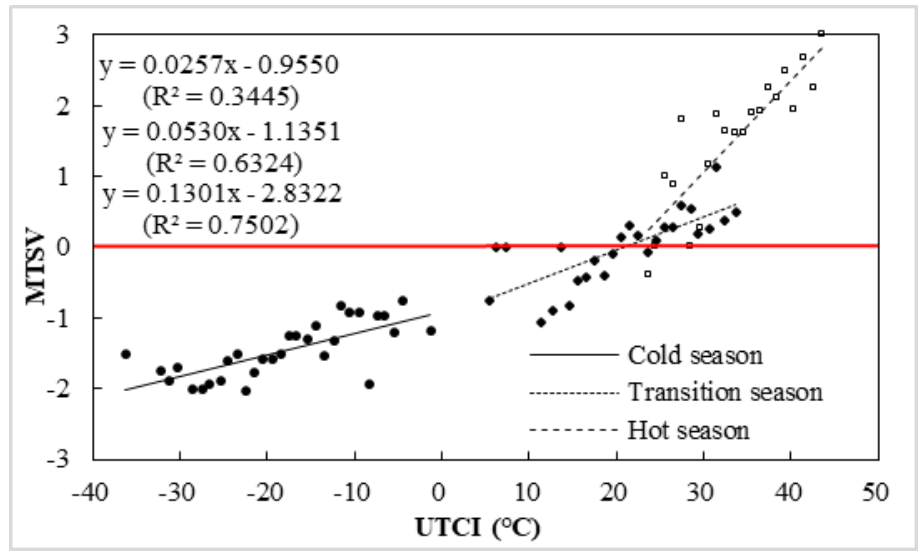

(a) UTCl and thermal sensation fitting curve

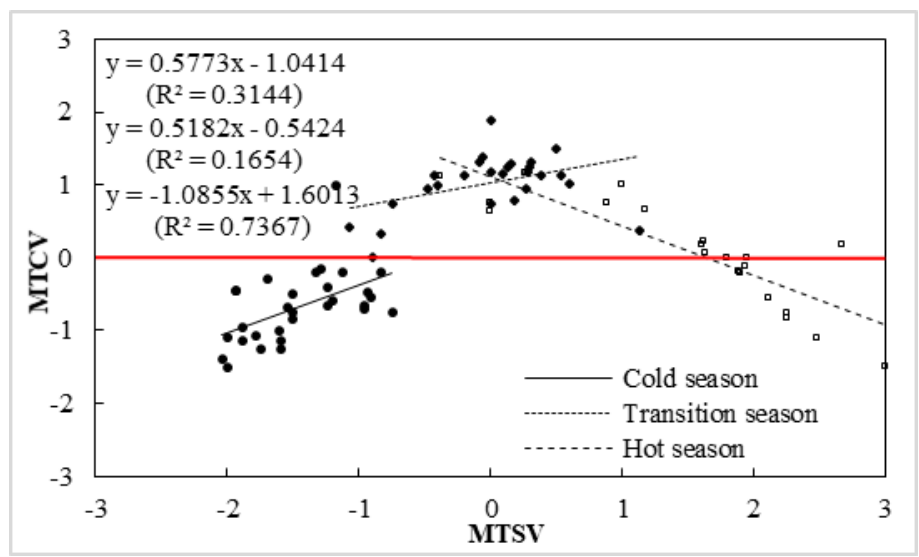

(b) Thermal sensation and thermal comfort fitting curve

Fig. 5. Fitting curves of UTCI, thermal sensation and thermal comfort.

\subsubsection{Preferred UTCI}

The expected temperature of people on the streets is related to the UTCl. According to correlation analysis, they expect the temperature to rise when the UTCl is low and the temperature to decrease when the UTCl is high, which indicates that there is significant correlation between the two cases (correlation coefficient $-0.445, P=0.000$ ). The method proposed by Lin et al. [12] was adopted to classify people's expectations on temperature. All datasets were sorted into bins, each corresponding to a $2{ }^{\circ} \mathrm{C} \mathrm{UTCl}$ interval; Fig. 6 shows a plot of the subjects' thermal preferences within each bin, together with the corresponding mean 
values of the relevant physical microclimatic parameters for the bins. As shown in Fig. 6 , when the $\mathrm{UTCl}$ is in the range of approximately $26-30{ }^{\circ} \mathrm{C}$ (air temperature of $20.0-24.9{ }^{\circ} \mathrm{C}$ ), the proportion of people with thermal expectation is lowest, and the proportions of people who prefer temperature increase and temperature decrease are equal. It can be observed that people have no expectations of temperature within this UTCI range. Fig. 5 (a) shows that the MTSV corresponding to $\mathrm{UTCl}$ at $26-30^{\circ} \mathrm{C}$ is in the range of $0-1$, which indicates that people have the least thermal expectation when they feel 'neutral-slightly warm'. In the process of increasing the $\mathrm{UTCl}$ from $30^{\circ} \mathrm{C}$ to $40^{\circ} \mathrm{C}$, the proportion of people who expect the temperature to decrease gradually increases. When the UTCI is in the range of $-30-4{ }^{\circ} \mathrm{C}$, the proportion of people who expect temperature floating is approximately $70 \%$. When the UTCI decreases to $-32{ }^{\circ} \mathrm{C}$, the proportion of people who expect the temperature to rise increases to $100 \%$, as people have the coldest feeling.

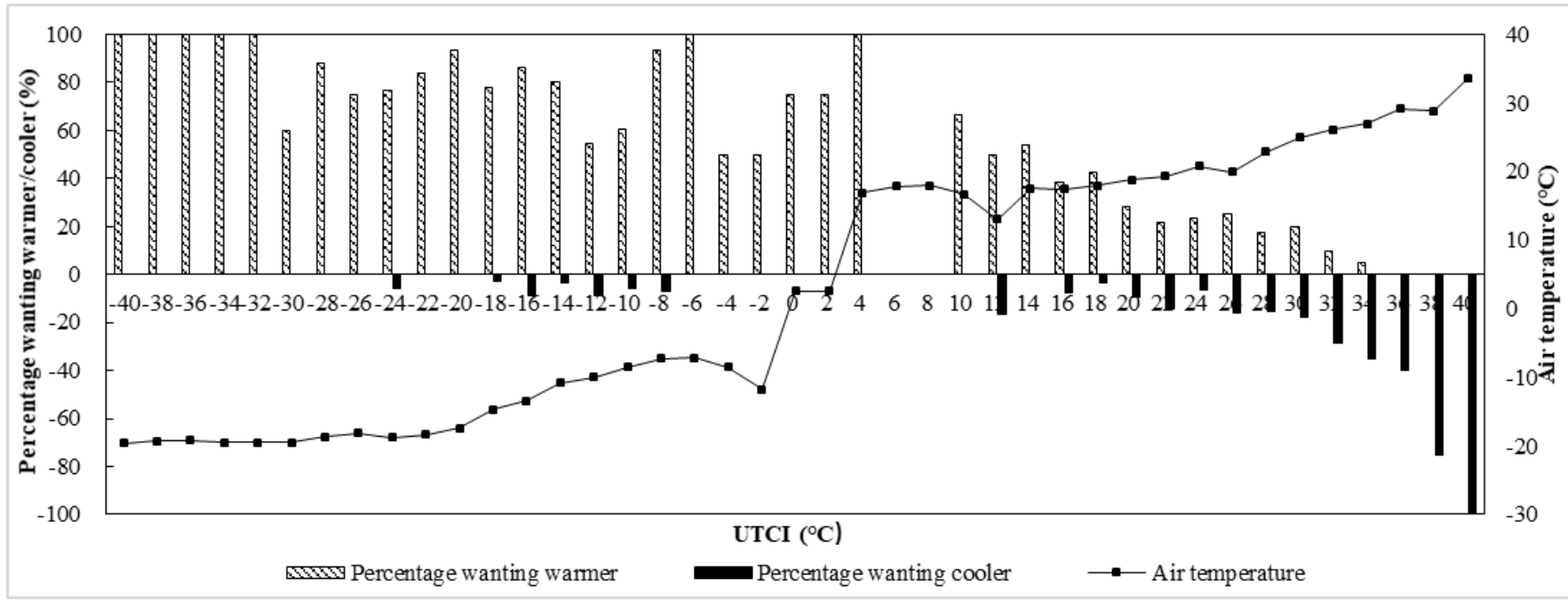

Fig. 6. Proportion of people expecting temperature increase or decrease. $*$ Negative values represent the proportion of people expecting temperature decrease, whereas positive values represent the proportion of people expecting temperature increase. $*$ Missing value is supplemented by the average of two adjacent values.

It can be observed from the above results that there may be a preferred temperature within the UTCI range for the transition and hot seasons. Thus, probit analysis was applied to calculate the preferred temperature based on expectation votes using the method proposed by Dear and Fountain [31] in the transition and hot seasons. The percentage of thermal expectation voting value was calculated at each $1{ }^{\circ} \mathrm{C}$ UTCl interval, and the percentage for each preference was calculated within each group and fitted with the probit model separately. The intersection point of the two curves is the preferred temperature, as shown in Fig. 7. The preferred temperatures in the transition and hot seasons were determined as $30.4{ }^{\circ} \mathrm{C}$ and $26.8^{\circ} \mathrm{C} \mathrm{UTCl}$, respectively. It can be observed from the results in Section 3.1.2 that people on the streets are less sensitive to the environment and more comfortable in a high temperature environment in the transition season than in the hot season; therefore, the expected temperature is higher in the transition season. Thus, according to Fig. 5 (b), people on the streets feel more comfortable when they feel hot in the transition season and more comfortable when it is cold during the hot season. In addition, since the UTCI range for the transition season fluctuates within the comfort range felt by people, the sensitivity of people in the thermal environment will be reduced. This indicates that in the same thermal sensation state, the UTCI value corresponding to the transition season is higher, so that the preferred UTCI in the transition season is also higher. The corresponding TSV values of the preferred UTCI can be obtained by inserting the preferred UTCI in the transition and hot seasons into Eqs. (6) and (7). The results are 0.48 and 0.65 for the transition 
and hot seasons, respectively. Therefore, people mostly expect a 'neutral-slightly warm' sensation state. The preferred TSV value in the hot season is higher than that in the transition season, as the experience in the hot season makes people on the streets more adaptable to higher thermal sensation. However, in the Taiwan region, the TSV values corresponding to the preferred temperature are -0.14 and -0.13 in the cold and hot seasons, respectively. People mostly anticipate a 'neutral-slightly cool' thermal sensation state [4], which indicates that different regions have different outdoor thermal environments. Therefore, people's expectations of a thermal environment vary.

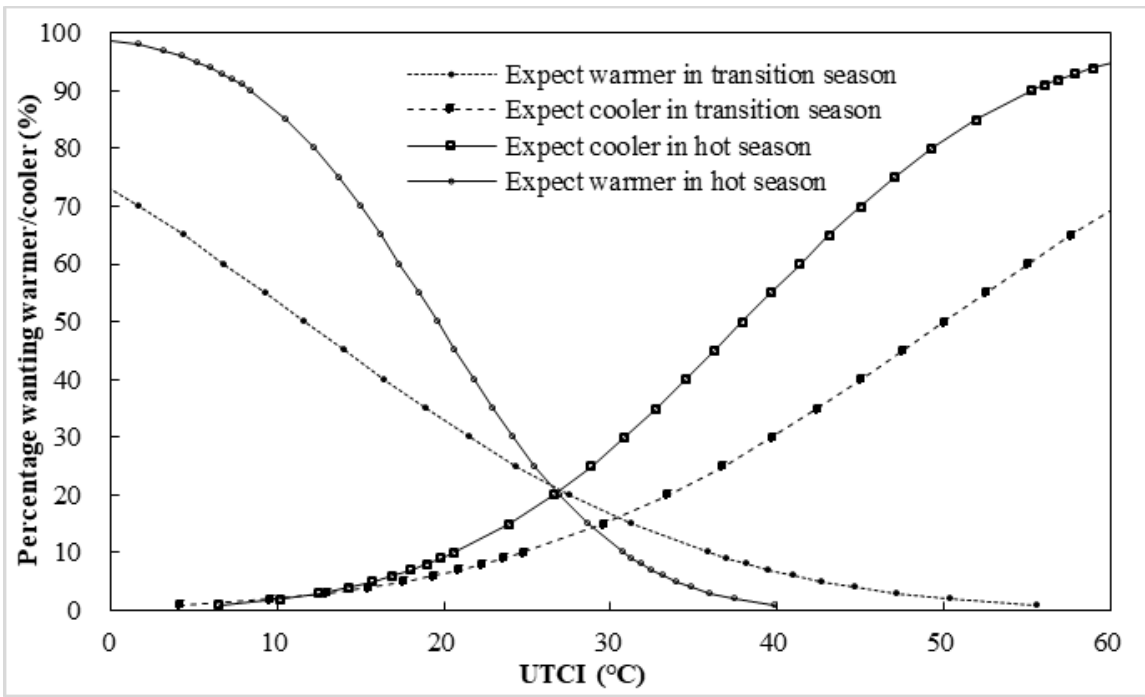

Fig. 7. Probabilistic model fitting of percentage of expected votes in the transition and hot seasons.

\subsubsection{Comparison of the modified UTCI with other regions}

The thermal comfort range varies from region to region owing to the influence of thermal adaptation; therefore, three regions with a high annual temperature range, including Harbin, were selected for comparison. By adopting the method proposed in the study of the Mediterranean region [29], this study matches the UTCl stress category and results of the unacceptable voting value presented in Section 3.1.1, as presented in Table 1. It is obvious that the modified UTCI varies significantly from region to region. According to meteorological data from 1988 to 2010, the annual variations of air temperature in Harbin and Tianjin are -17.5$23.2^{\circ} \mathrm{C}$ and $-3-26{ }^{\circ} \mathrm{C}$, respectively. The UTCI value for extreme cold stress in Harbin is $9.2^{\circ} \mathrm{C}$ less than that in Tianjin and those of extreme heat stress in Harbin and Tianjin are not significantly different, which indicates that there is a clear correlation between the modified UTCI and temperature variations throughout the year [9]. Continuous low temperature in cold winter makes people on the streets more adaptable to the cold environment. The modified UTCI range, which is the range between extreme cold stress and extreme heat stress, of the Mediterranean region is significantly smaller compared to those of Harbin and Tianjin in China, which indicates that people in the Mediterranean region have a low adaptable range for the thermal environment [29]. 
Table 1

Comparison of modified UTCI in different regions.

\begin{tabular}{|c|c|c|c|c|}
\hline Stress category & UTCI $\left({ }^{\circ} \mathrm{C}\right)$ & $\begin{array}{l}\text { Modified UTCI for } \\
\text { the Mediterranean } \\
\text { region }\left({ }^{\circ} \text { C) }[29]\right.\end{array}$ & $\begin{array}{c}\text { Modified UTCI for } \\
\text { Tianjin, China }\left({ }^{\circ} \mathrm{C}\right) \\
{[9]}\end{array}$ & $\begin{array}{c}\text { Modified UTCI for } \\
\text { Harbin, China }\left({ }^{\circ} \mathrm{C}\right)\end{array}$ \\
\hline Extreme cold stress & $<-40$ & $<4.1$ & $<-21$ & $<-30.2$ \\
\hline Very strong cold stress & -40 to -27 & 4.1 to 5.9 & -21 to- 16 & -30.2 to -25.6 \\
\hline Strong cold stress & -27 to -13 & 5.9 to 9.1 & -16 to- 11 & -25.6 to -18.3 \\
\hline Moderate cold stress & -13 to 0 & 9.1 to 14.0 & -11 to -6 & -18.3 to -7.2 \\
\hline Slight cold stress & 0 to 9 & 14.0 to 17.4 & -6 to 12 & -7.2 to -3.8 \\
\hline No thermal stress & 9 to 26 & 17.4 to 24.5 & 12 to 25 & -3.8 to 23.0 \\
\hline Moderate heat stress & 26 to 32 & 24.5 to 29.1 & 25 to 33 & 23.0 to 29.1 \\
\hline Strong heat stress & 32 to 38 & 29.1 to 34.1 & 33 to 39 & 29.1 to 40.9 \\
\hline Very strong heat stress & 38 to 46 & 34.1 to 37.7 & 39 to 47 & 40.9 to 49.4 \\
\hline Extreme heat stress & $>46$ & $>37.7$ & $>47$ & $>49.4$ \\
\hline
\end{tabular}

\subsubsection{Comparison of the modified UTCI with other regions}

In the same area, the thermal comfort of different seasons is also different. For example, in Harbin (Table 2), the neutral temperatures in the transition season and the hot season are similar. However, the sensitivity in the hot season is higher than in the transition season. In the hot season, the comfort TSV is below 1.5, and people on the streets in the transition season are generally in a comfortable state. The preferred $\mathrm{UTCl}$ in the transition season is higher than that in the hot season, and the corresponding TSV value is lower than that in the hot season. People on the streets expect the 'neutral-slightly warm' feeling state in the transition and hot seasons.

Although people on the streets have always been in a comfortable state in the transition season, there is still a preferred UTCI, indicating that people still have expectations for the thermal environment when they feel comfortable. In the hot season, the comfortable UTCI is higher than the preferred UTCl, indicating that people can feel comfortable in the summer when they are 'slightly warm-warm' due to the influence of experience. However, people still expect a cooler thermal environment. In the cold season, neutral, comfortable, and preferred temperatures are not present due to the low temperature and the harsh climate. Therefore, these conditions will not be discussed. 
Table 2

Comparison of neutral, comfortable, and preferred temperatures in different seasons.

\begin{tabular}{|c|c|c|c|c|c|c|}
\hline & \multicolumn{2}{|c|}{ Cold season } & \multicolumn{2}{|c|}{ Transition season } & \multicolumn{2}{|c|}{ Hot season } \\
\hline & UTCI & TSV & UTCI & TSV & UTCI & TSV \\
\hline Neutral UTCI $(T S V=0)$ & - & - & $=21.4^{\circ} \mathrm{C}$ & $=0$ & $=21.8^{\circ} \mathrm{C}$ & $=0$ \\
\hline Comfortable UTCI $(\mathrm{TCV} \geq 0)$ & - & - & - & - & $\leq 33.3^{\circ} \mathrm{C}$ & $\leq 1.5$ \\
\hline Preferred UTCI & - & - & $=30.4^{\circ} \mathrm{C}$ & $=0.48$ & $=26.8^{\circ} \mathrm{C}$ & $=0.65$ \\
\hline
\end{tabular}

\subsection{Factors that influence thermal comfort}

\subsubsection{Thermal environment adaptation}

People adopt different measures in different thermal environments to improve thermal comfort. As shown in Fig. 8, people adopt four basic measures to improve thermal comfort, and their adopted schemes vary significantly depending on the season. In the cold season, $40.6 \%$ of people preferred to stay inside the room, whereas $23.9 \%$ and $23.4 \%$ of the people chose exposure to sunshine and exercise, respectively. In the transition season, $40.8 \%$ of people preferred to enjoy the sunshine or stay in the shade, $31.4 \%$ opted to exercise, and $17.3 \%$ preferred to stay inside the room. In the hot season, $43.8 \%$ of people chose to stay in the shade, $38.0 \%$ preferred to stay inside the room, and only $12.1 \%$ opted to exercise. It can be observed that in the harsh environments of the cold and hot seasons, people tend to stay in a room to escape the harsh thermal environment. People on the streets in the hot season prefer to stay in the shade, whereas in the cold season, people prefer to exercise to feel warmer. In the three seasons, people do not tend to increase or decrease the amount of clothing worn to improve comfort.

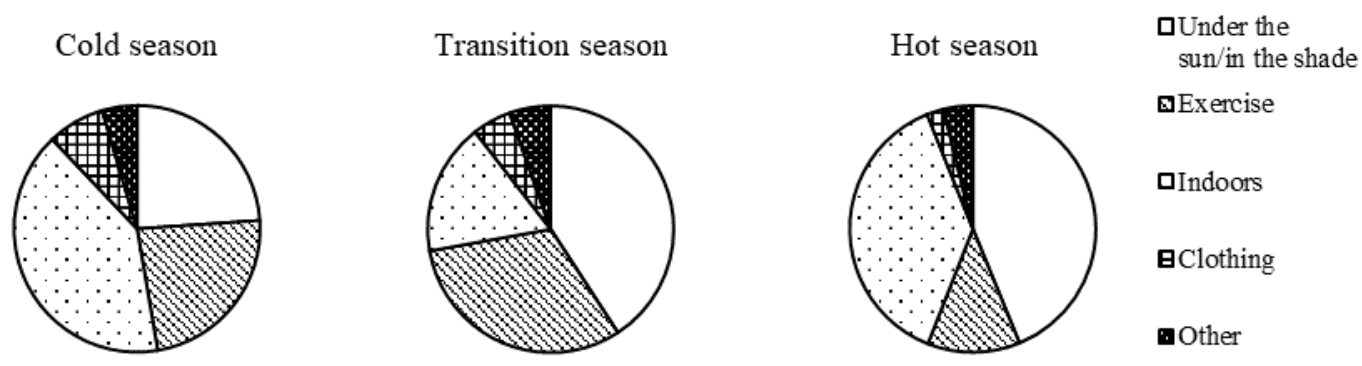

Fig. 8. Measures adopted by people on the streets to improve thermal comfort.

\subsubsection{Behaviour of people on the streets}

People who go out to the streets for different reasons have different levels of choices for the surrounding environment, which may affect their level of thermal comfort. Therefore, during the on-site investigation, participants were asked why they came to the street, and were given three options to choose from: to take a walk, which indicates that the purpose of coming is to relax by walking; for work, indicating that they are not free to leave the environment; and just passing, indicating that the street is just part of the participant's journey.

The MTCVs of people coming to the street for different reasons were compared as shown in Fig. 9. There is a minimal difference in the thermal comfort levels among people with different 
perceived control states in the transition and hot seasons. However, in the cold season, people with higher levels of freedom feel more comfortable, and the MTCV of working people is 0.42 and 0.96 lower than the MTCVs of people passing by and walking, respectively. The analysis of variance shows significant differences between the three options in the cold season (working and passing by: average difference $0.419 ; \mathrm{P}=0.050$; passing by and walking: average difference 0.533; $P=0.000$; working and walking: average difference 0.952; $P=0.000$ ). This indicates that whether the environment can be selected freely in the cold season significantly influences the tolerance and acceptance of people on the streets to the thermal environment. When people are freer, they have a greater range of choices for the thermal environment, which helps them endure the harsh environment so that their satisfaction will be higher. There is no significant difference in thermal comfort among people with different behaviours during the transition season and the hot season.

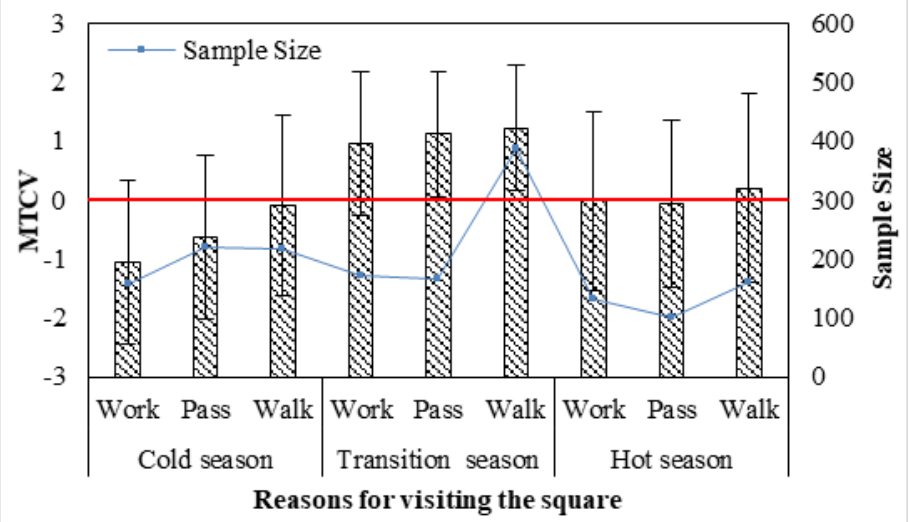

Fig. 9. Mean TCV and standard deviation of thermal comfort of people with different behaviours in each season.

\subsubsection{Local residence time}

The experience of a person's thermal environment in a certain area is mainly determined by his residence time in the area, which is also limited by his or her age (here, age means the maximum duration of living in the country). Therefore, to exclude the influence of age on residence time, people aged 18-30 participated in the study. As shown in Fig. 10, the longer people live in the area, the hotter they will feel in the three seasons, but the change is minimal, not more than 0.4 scale. However, change in the TCV increases with the increase in the residence time particularly in the cold season (correlation coefficient $0.26 ; P=0.001$ ). The mean TCV of people with residence time of less than one year is lower by 0.80 compared to that of people with residence time of over nine years. That is, when people who have resided in the area longer than nine years feel 'just comfortable', people who have resided in the area less than one year feel 'just uncomfortable'. This is because people who have resided in cold regions for a long time have more experience in the thermal environment of cold regions, and hence are more adaptable to colder environment. 


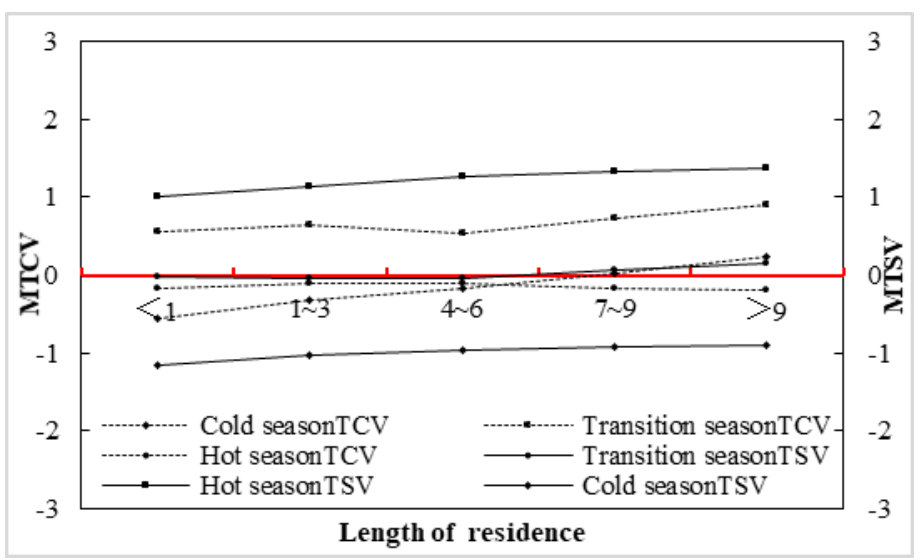

Fig. 10. Mean TCV and TSV of different local residence times in each season.

\subsubsection{Gender}

One of the major factors that influence thermal comfort is demographic factors, such as gender and age. The mean TCV and TSV of males and females were compared in different seasons. As shown in Fig. 11, the mean TCV of females in all seasons is lower than that of males. A ttest of the TCV and TSV of males and females in all seasons indicates that during the hot season, male participants feel more comfortable $(P=0.026)$, and in the cold season, female participants feel colder $(P=0.030)$. There is no significant difference in the thermal comfort for males and females in other seasons.

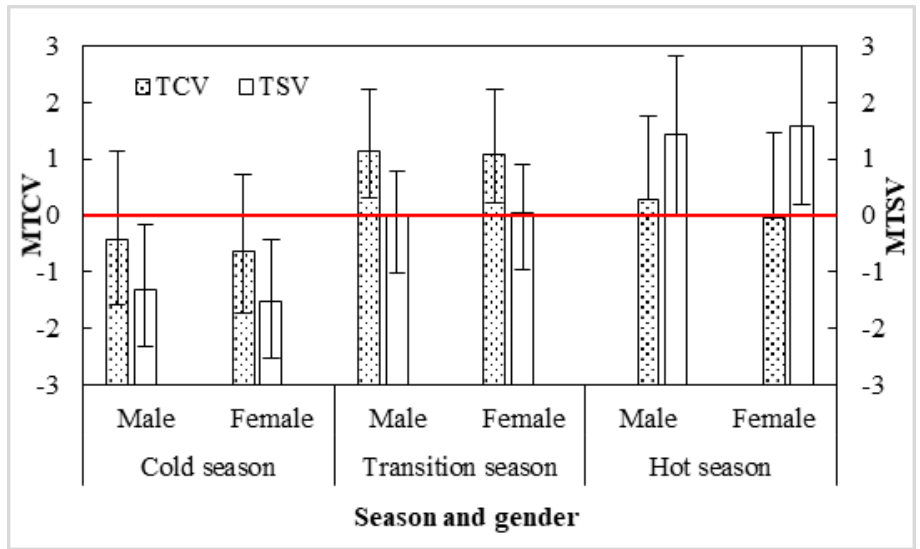

Fig. 11. Mean TCV, TSV, and standard deviation of different genders in each season.

\subsubsection{Age}

The residence time of different age groups may be different. Therefore, to exclude the influence of the local residence time, only those who have resided in the local area for more than nine years participated in the study to carry out a comparison of the age. As shown in Fig. 12, the higher the average age, the higher the mean TSV in the cold season. Correlation analysis of the age and TSV indicates that age is related to TSV in the cold season. The older the participants, the higher the mean TSV (correlation coefficient $0.14 ; \mathrm{P}=0.014$ ). In the hot season, the older the participants, the lower the mean TSV (correlation coefficient $-0.32 ; P=0.000$ ). Data analysis of age and clothing thermal resistance shows that there is no significant difference in clothing thermal resistance across different age groups. This result indicates that older participants are more adaptable to harsh thermal environments. In the transition season, the TSV of different age groups remains the same, that is, approximately 0 . However, the 18- 
30 age group participants feel hotter (correlation coefficient $-0.20 ; P=0.000$ ). There is a clear correlation between TCV and age in the hot season (correlation coefficient $0.28 ; P=0.000$ ), in which older participants feel more comfortable. In other seasons, we found no correlation between TCV and age.

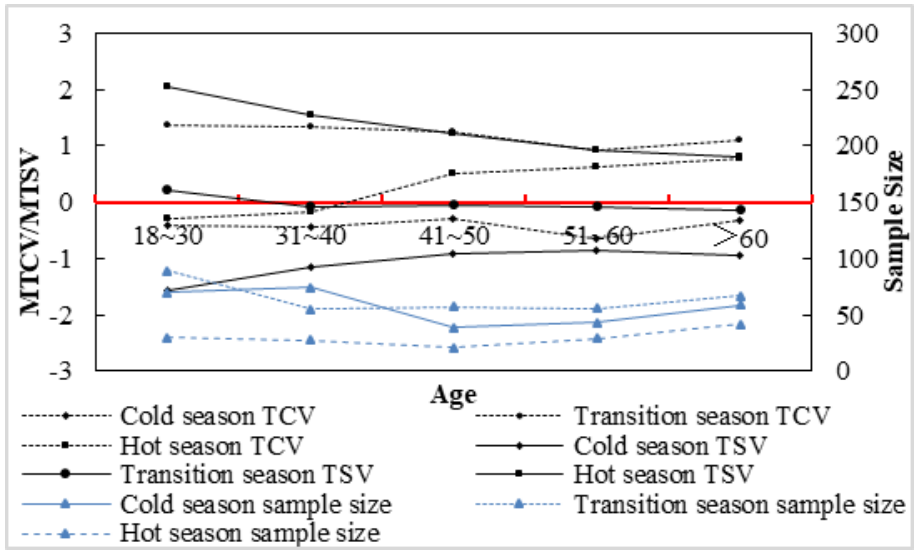

Fig. 12. Mean TCV and TSV of people with different ages in each season

\section{Conclusions}

This study investigated the main factors that influence the thermal comfort of people on the streets in severe cold regions of northeast China. The study determined the UTCI range that represented the feeling of comfort of people on the streets and developed a thermal comfort evaluation model based on UTCI in Harbin. The influence of thermal adaptation factors and demographic factors on the thermal comfort of people on the streets was analysed.

The thermal sensation range of people on the streets reached the typical standard of $-3.8-$ $23.0^{\circ} \mathrm{C} \mathrm{UTCl}$ all year round. The neutral temperatures in the transition and hot seasons were $21.4{ }^{\circ} \mathrm{C}$ and $21.8^{\circ} \mathrm{C} \mathrm{UTCl}$, respectively. People on the streets were more sensitive to the environment during the hot season. Meanwhile, in the cold season, people on the streets experienced an uncomfortable environment, whereas they were comfortable during the transition season and when the TSV was 1.5 or less in the hot season. The preferred temperatures for the transition and hot seasons were $30.4{ }^{\circ} \mathrm{C}$ and $26.8^{\circ} \mathrm{C} \mathrm{UTCl}$, respectively, and the corresponding TSV values were 0.48 and 0.65 . In severe cold regions, people mostly expected a 'neutral-slightly warm' thermal sensation state. The Harbin's modified UTCI range was larger compared to those of other regions, and the extreme cold stress reached $-30.2^{\circ} \mathrm{C}$, which was significantly lower than those of Tianjin and the Mediterranean. Although people have been in a comfortable state during the transition season, there was still a preferred UTCI, as they also expected an improved environment. People can also feel comfortable during hot season when it is 'slightly warm-warm' owing to experience. However, the comfortable UTCl was higher than the preferred UTCI, which indicates that people still expected a cooler thermal environment.

Environmental adaptation influenced outdoor thermal comfort. People tended to adopt different measures to achieve comfort in different seasons. The most likely measure was exposure to sunshine/move to the shade or to enter a room. The behaviours of people were also another important aspect of their thermal comfort. The thermal comfort of people with different behaviours was significantly different, and those who walked felt most comfortable in the cold season. The longer people reside in the local region, the more adaptable they will become to the local outdoor environment. The thermal comfort level in the cold season increased with an increase in the actual duration of residence. Different genders also have different feelings of 
Hong Jin, Siqi Liu \& Jian Kang: Energy and Buildings doi: 10.1016/j.enbuild.2019.05.054

thermal comfort. In all seasons, the TCV for female participants was lower than that of male participants. The older the participants, the more adaptable they were to the extreme environment. In the cold season, the older the participants, the higher the mean TSV, whereas in the hot season, the older the participants, the lower the mean TSV, whereas in the hot season, the older the participants, the lower the average TSV.

\section{Declaration of Competing Interest}

None.

\section{Acknowledgements}

The authors would like to thank all respondents who participated in this study.

\section{Funding}

This work was supported by the National Natural Science Foundation of China [grant number 51438005]. 


\section{References}

[1] I. Eliasson, I. Knez, U Westerberg, S. Thorsson, F. Lindberg, Climate and behaviour in a Nordic city, Landsc. Urban Plan. 82 (2007) 72-84, doi: 10.1016/j. landurbplan.2007.01.020.

[2] I. Knez, S. Thorsson, Influences of culture and environmental attitude on thermal, emotional and perceptual evaluations of a public square, Int. J. Biometeorol. 50 (2006) 258-268, doi: 10.1007/s00484- 006- $0024-0$.

[3] Y.M. Jin, J. Kang, H. Jin, Z.Y. Yu, Effects of openings on the wind-sound environment in the traditional residential streets in a severe cold city of China, Environ. Plan. B Urban Anal. City Sci. (2018) 1-18 (in press), doi: 10.1177/ 2399808318805490.

[4] T.P. Lin, Thermal perception, adaptation and attendance in a public square in hot and humid regions, Build. Environ. 44 (2009) 2017-2026, doi: 10.1016/j. buildenv.20 09.02.0 04.

[5] A. Middel, N. Selover, B. Hagen, N. Chhetri, Impact of shade on outdoor thermal comfort-a seasonal field study in Tempe, Arizona, Int. J. Biometeorol. 60 (2016) 1-13, doi: 10.10 07/s0 0484- 016- 1172- 5.

[6] L. Chen, Y. Wen, L. Zhang, W.N. Xiang, Studies of thermal comfort and space use in an urban park square in cool and cold seasons in Shanghai, Build. Environ. 94 (2015) 644-653, doi: 10.1016/j.buildenv.2015.10.020.

[7] S. Watanabe, K. Nagano, I. Jin, T. Horikoshi, Evaluation of outdoor thermal comfort in sunlight, building shade, and pergola shade during summer in a humid subtropical region, Build. Environ. 82 (2014) 556-565, doi: 10.1016/j.buildenv. 2014.10.002.

[8] S. Provençal1, O. Bergeron, R. Leduc, N. Barrette, Thermal comfort in Quebec City, Canada: sensitivity analysis of the UTCl and other popular thermal comfort indices in a mid-latitude continental city, Int. J. Biometeorol. 60 (2016) 591-603, doi: 10.10 07/s0 0484- 015- 1054- 2.

[9] D. Lai, D. Guo, Y. Hou, C. Lin, Q. Chen, Studies of outdoor thermal comfort in northern China, Build. Environ. 77 (2014) 110-118, doi: 10.1016/j.buildenv.2014. 03.026.

[10] M. Nikolopoulou, S. Lykoudis, Thermal comfort in outdoor urban spaces: analysis across different European countries, Build. Environ. 41 (2006) 1455-1470, doi: 10.1016/j.buildenv.2005.05.031.

[11] A. Pitts, Thermal comfort in transition spaces, Buildings 3 (2013) 122-142, doi: 10.3390/buildings3010122.

[12] T.P. Lin, R.D. Dear, R.L. Hwang, Effect of thermal adaptation on seasonal outdoor thermal comfort, Int. J. Climatol. 31 (2011) 302-312, doi: 10.1002/joc.2120.

[13] L. Chen, E.. Ng, Outdoor thermal comfort and outdoor activities: a review of research in the past decade, Cities 29 (2012) 118-125, doi: 10.1016/j.cities.2011. 08.006.

[14] H. Andrade, M.J. Alcoforado, S. Oliveira, Perception of temperature and wind by users of public outdoor spaces: relationships with weather parameters and personal characteristics, Int. J. Biometeorol. 55 (2011) 665-680, doi: 10.1007/ s00484- 010- 0379- 0.

[15] L. Lan, Z. Lian, W. Liu, Y. Liu, Investigation of gender difference in thermal comfort for Chinese people, Eur. J. Appl. Physiol. 102 (2008) 471-480, doi: 10.10 07/s0 0421-0 07- 0609- 2.

[16] J. Yin, Y. Zheng, R. Wu, J. Tan, D. Ye, W. Wang, An analysis of influential factors on outdoor thermal comfort in summer, Int. J. Biometeorol. 56 (2012) 941, doi: 10.10 07/s0 0484- 011- 0503- 9.

[17] Ministry of Housing and Urban-Rural Development of the People's Republic of China, GB 50352-2005 Code for Design of Civil Buildings, China Architecture \& Building Press, 2005.

[18] Y. Xiao, L. Wang, M. Yu, H. Liu, J. Liu, Effects of source emission and window opening on winter indoor particle concentrations in the severe cold region of China, Build. Environ. 144 (2018) 23-33, doi: 10.1016/j.buildenv.2018.08.001.

[19] Z. Wang, Y. Ji, J. Ren, Thermal adaptation in overheated residential buildings in severe cold area in China, Energy Build. 146 (2017) 322-332, doi: 10.1016/j. enbuild.2017.04.053.

[20] S.Y. Liu. (June 22, 2014). The opening hours of Harbin Central Street is extended again, daily average passenger traffic reached a new high of 500000. Retrieved April 16, 2019, form http://hlj.people.com.cn/n/2014/0622/ c220027-21481037.html.

[21] H.Y. Yuan. (June 2, 2017). The little train operate day and night at Children's park in Harbin. Retrieved April 16, 2019, Form http://hlj.ifeng.com/a/20170602/5719274_0.shtml.

[22] ISO, International Standard 7726, Ergonomics of the Thermal Environment-Instruments and Method for Measuring Physical Quantities, International Standard Organization, Geneva, 1998.

[23] M. Luo, X. Zhou, Y. Zhu, J. Sundell, Revisiting an overlooked parameter in thermal comfort studies, the metabolic rate, Energy Build. 118 (2016) 152-159, doi: 10.1016/j.enbuild.2016.02.041.

[24] E. Glaser, The Physiological Basis of Habituation, Oxford University Press, London, 1966.

[25] E. Gold, The effect of wind, temperature, humidity and sunshine on the loss of heat of a body at temperature 98 F, Q. J. R. Meteorol. Soc. 61 (2010) 316-346, doi: 10.1002/qj.49706126104.

[26] P. Weihs, H. Staiger, B. Tinz, E. Batchvarova, H. Rieder, L. Vuilleumier, M. Maturilli, G. Jendritzky, The uncertainty of UTCl due to uncertainties in the determination of radiation fluxes derived from measured and observed meteorological data, Int. J. Biometeorol. 56 (2012) 537-555, doi: 10. 10 07/s0 0484- 011- $0416-7$. 
[27] D. Fiala, K.J. Lomas, M. Stohrer, Computer prediction of human thermoregulatory and temperature responses to a wide range of environmental conditions, Int. J. Biometeorol. 45 (2001) 143-159, doi: 10.10 07/s0 0484010 0 .

[28] G. Havenith, D. Fiala, K. Błazejczyk, M. Richards, P. Bröde, I. Holmér, H. Rintamaki, Y. Benshabat, G. Jendritzky, The UTCl-clothing model, Int. J. Biometeorol. 56 (2012) 461-470, doi: 10.10 07/s0 0484- 011- 0451- 4.

[29] K. Pantavou, G. Theoharatos, M. Santamouris, D. Asimakopoulos, Outdoor thermal sensation of pedestrians in a Mediterranean climate and a comparison with UTCI, Build. Environ. 66 (2013) 82-95, doi: 10.1016/j.buildenv. 2013.02.014.

[30] S. Park, S.E. Tuller, M. Jo, Application of Universal Thermal Climate Index (UTCI) for microclimatic analysis in urban thermal environments, Landsc. Urban Plan. 125 (2014) 146-155, doi: 10.1016/j.landurbplan.2014.02.01 .

[31] R.J.D. Dear , M.E. Fountain , Field experiments on occupant comfort and office thermal environments in a hothumid climate, ASHRAE Trans. 100 (1994) 457-474.

[32] J. Han, G. Zhang, Q. Zhang, J. Zhang, J. Liu, L. Tian, Y. Liu, Field study on occupants' thermal comfort and residential thermal environment in a hot-humid climate of China, Build. Environ. 42.12 (2007) 4043-4050, doi: 10.1016/ j.buildenv.2006.06.028.

[33] J. Han, W. Yang, J. Zhou, G. Zhang, Q. Zhang, D.J. Moschandreas, A comparative analysis of urban and rural residential thermal comfort under natural ventilation environment, Energy Build. 41.2 (2009) 139-145, doi: 10.1016/j.enbuild. 20 08.08.0 05.

[34] S. Shooshtarian, I. Ridley, The effect of individual and social environments on the users thermal perceptions of educational urban precincts, Sustain. Cities Soc. 26 (2016) 119-133, doi: 10.1016/j.scs.2016.06.005.

[35] Y. Wang, Z. Ni, Y. Peng, B. Xia, Local variation of outdoor thermal comfort in different urban green spaces in Guangzhou, a subtropical city in South China, Urban For. Urban Green. 32 (2018) 99-112, doi: 10.1016/j.ufug.2018.04.005.

[36] P.K. Cheung, C.Y. Jim, Improved assessment of outdoor thermal comfort: 1-hour acceptable temperature range, Build. Environ. 151 (2019) 303-317, doi: 10.1016/ j.buildenv.2019.01.057.

[37] P. Cohen, O. Potchter, A. Matzarakis, Human thermal perception of Coastal Mediterranean outdoor urban environments, Appl. Geogr. 37 (2013) 1-10, doi: 10.1016/j.apgeog.2012.11.001.

[38] L. Yang, H. Yan, Y. Xu, J.C. Lam, Residential thermal environment in cold climates at high altitudes and building energy use implications, Energy Build. 62 (2013) 139-145, doi: 10.1016/j.enbuild.2013.02.058.

[39] R.L. Hwang, T.P. Lin, C.P. Chen, N.J. Kuo, Investigating the adaptive model of thermal comfort for naturally ventilated school buildings in Taiwan, Int. J. Biometeorol. 53.2 (2009) 189-200, doi: 10.1007/s00484- 008- 02032.

[40] T.P. Lin, K.T. Tsai, C.C. Liao, Y.C. Huang, Effects of thermal comfort and adaptation on park attendance regarding different shading levels and activity types, Build. Environ. 59 (2013) 599-611, doi: 10.1016/j.buildenv.2012.10.005.

[41] ASHRAE, ASHRAE Standard 55-2004, Thermal Environmental Conditions for Human Occupancy, American Society of Heating, Refrigerating and Air-Conditioning Engineers, Inc, Atlanta, 2004.

[42] J.F. Wohlwill, Human adaptation to levels of environmental stimulation, Hum. Ecol. 2 (1974) 127-147, doi: 10.1007/BF01558117. 